\title{
Selected Diagnoses in Hospitalized Patients in Palliative Care
}

\section{R. Didic (Richard Didic)', M. Samohyl(Martin Samohyl)2, R. Babela (RobertBabela) ${ }^{1.3}$}

${ }^{1}$ St. Elisabeth University of Health and Social Science, Bratislava,

\section{Original Article} Slovakia

${ }^{2}$ Institute of Hygiene, Faculty of Medicine, Comenius University in Bratislava, Slovakia

${ }^{3}$ HADM, University of Scranton, PA, USA

\section{E-mail address:}

martin.samohyl@fmed.uniba.sk

\section{Reprint address:}

Martin Samohyl

Institute of Hygiene LFUK

Bratislava

Slovakia

Source: Clinical Social Work and Health Intervention

Volume: 10

Issue: 2

Pages: $40-42$

Cited references: 3

\section{Reviewers:}

Selvaraj Subramanian

SAAaRMM, Kuala Lumpur, Malaysia

Harald Stefan

Vienna General Hospital, Vienna, Austria

\section{Key words:}

Hospitalized Patients. Palliative Care. Palliative Patients.

\section{Publisher:}

International Society of Applied Preventive Medicine i-gap

CSWHI 2019; 10(2): 40 - 42; DOI 10.22359/cswhi_10_2_06 @ 2019 Clinical Social Work and Health Intervention

\section{Abstract:}

Objective: The aim was the evaluation of the most common diagnoses in hospitalized patients in palliative care in Slovakia, 2016-2017.

Design: Descriptive study.

Participants: We analyzed 8,404 hospitalized patients in palliative care. 
Methods: The data were provided by the General Health Insurance Company in Slovakia. The proportions statistical analysis and average percentage differences (APD) analysis were evaluated by IBM SPSS Statistics.

Results: Mental and behavioral disorders due to use of alcohol were observed as the most common diagnoses in hospitalized patients in palliative care in Slovakia (2016: 69.8\% and 2017: 68.6\%) with decrease of APD about $0.5 \%$.

Conclusion: We assume that the mental and behavioral disorders due to use of alcohol were patients' secondary diagnoses for which they were hospitalized as a result of primary incurable diagnoses.

\section{To the Editor}

Palliative care is the multidisciplinary specialty whose aim is to improve quality of life of patients with incurable disease (1).

The aim was evaluation of the most common diagnoses in hospitalized patients in palliative care in Slovakia, 2016-2017.

In this descriptive study, the data were provided by the General Health Insurance Company in Slovakia. It analyzed 8,404 hospitalized patients in palliative care according to the most common diagnoses. The most common diagnoses were: mental and behavioral disorders due to use of alcohol $(n=6,036)$; mental and behavioral disorders due to use of synthetic narcotics $(n=1,119)$; fracture of neck of femur (fractured hip) $(n=743)$; chronic ischemic heart disease $(n=506)$.
The proportions statistical analysis and average percentage differences (APD) analysis were evaluated by IBM SPSS Statistics. The APD was calculated: APD $=x^{1 * 100 /}$ $\mathrm{x}^{2}-100$, where, $\mathrm{x}^{1}$ is number hospitalized patients in palliative care in 2017 and $x^{2}$ is number hospitalized patients in palliative care in 2016.

The most common diagnoses in hospitalized patients in palliative care in Slovakia, 2016-2017 are presented in the Table 1. Mental and behavioral disorders due to use of alcohol were observed as the most common diagnoses in hospitalized patients in palliative care in Slovakia (2016: 69.8\% and 2017: $68.6 \%$ ) with a decrease of APD about $0.5 \%$. In case of incurable diseases, patients often consumed alcohol (2).

Table 1: The most common diagnoses in hospitalized patients in palliative care $(n=8,404)$ in Slovakia, 2016-2017

\begin{tabular}{|l|l|l|l|}
\hline $\begin{array}{l}\text { The most common diagnoses in hospitalized patients } \\
\text { in palliative } \text { care }^{1}\end{array}$ & $\begin{array}{l}\mathbf{2 0 1 6} \\
\mathrm{n}(\%)\end{array}$ & $\begin{array}{l}\mathbf{2 0 1 7} \\
\mathrm{n}(\%)\end{array}$ & $\begin{array}{l}\text { APC } \\
(\%)\end{array}$ \\
\hline Mental and behavioral disorders due to use of alcohol & $3,025(69.8)$ & $3,011(68.6)$ & $-0,5$ \\
\hline $\begin{array}{l}\text { Mental and behavioral disorders due to use of synthetic } \\
\text { narcotics }\end{array}$ & $571(13.2)$ & $548(12.5)$ & $-4,0$ \\
\hline Fracture of neck of femur & $351(8.1)$ & $392(8.9)$ & $11,7^{*}$ \\
\hline Chronic ischemic heart disease & $247(5.7)$ & $259(5.9)$ & $4,9^{*}$ \\
\hline
\end{tabular}

${ }^{*} \mathrm{p}<0.05 ;{ }^{1}$ the primary diagnoses with which the patients were hospitalized, secondary diagnoses were not analyzed 
Figure 1A-D: The most common diagnoses in hospitalized patients in palliative care $(n=8,404)$ in Slovakia, in the period 2016-2017
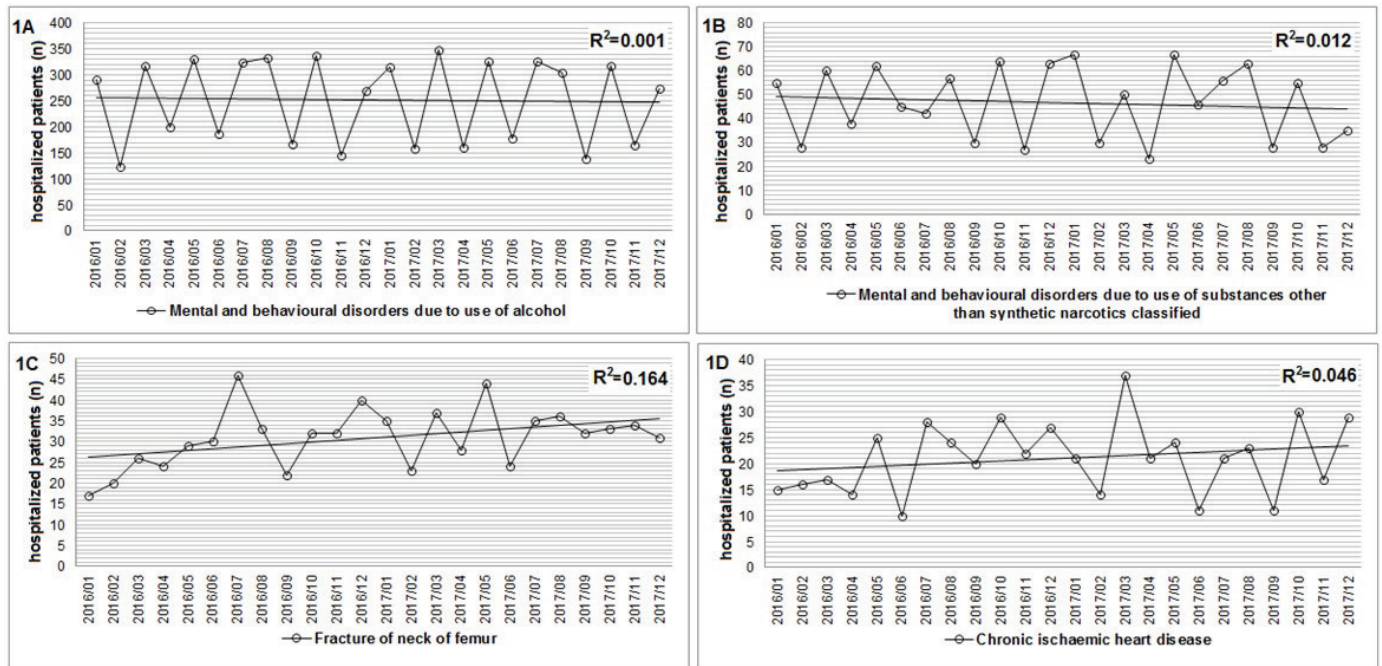

The significant increase of APD was found in fracture of neck of femur $(11.7 \%)$ and chronic ischemic heart disease $(4.9 \%)$ (Table 1 and Figure 1C-D).

We assume that the mental and behavioral disorders due to use of alcohol were patients' secondary diagnoses for which they were hospitalized as a result of primary incurable diagnoses - cancer, HIV (3) and other.

\section{References}

1. STANCIAK J, PECIOVA R. (2014) Psychosocial aspects of dying from view of nurses (in Slovak). In: Nursing without borders IV. Bratislava: Slovak Chamber of Nurses and Midwives, 272-276.
2. STANCIAK J, NOVOTNÝ J, PRIBYL $\mathrm{H}$, CECH T, NOVOTNY M, ALBERT M. (2005) Nursing and Alcoholism (in Slovak). In: New Trends in Nursing 4. Ceske Budejovice: University of South Bohemia, Faculty of Health and Social Studies, 388-420.

3. SHAHUM A, KALAVSKA A, CHABADOVA M, KALAVSKY E, BENCA J, MRAZOVA M, et al. (2017) Quality of Life, Risk Factors and Mortality in Children with HIV/AIDS on 2nd Line Treatment, Slow Progressors and Late Presenters in Cambodian Orphanage. Clinical Social Work and Health Intervention; 8 (2): 7-12. doi:10.22359/cswhi_8_2_01. 